\title{
O "PÓS-COLONIAL" COMO CATEGORIA DE ANÁLISE SOCIOLÓGICA DAS LITERATURAS PALOPIANAS: POSSIBILIDADES E LIMITES
}

\author{
EL "POSTCOLONIAL" COMO CATEGORÍA DE ANÁLISIS SOCIOLÓGICA DE LAS \\ LITERATURAS PALOPIANAS: POSIBILIDADES Y LÍMITES
}
THE "POSTCOLONIAL" AS A CATEGORY OF SOCIOLOGICAL ANALYSIS OF PALOPIAN LITERATURES: POSSIBILITIES AND LIMITS

\author{
Marco Aurelio de Oliveira LEAL ${ }^{1}$
}

RESUMO: O objetivo do artigo é colocar em questão os limites e as possibilidade dos aportes teóricos "pós-coloniais" para a análise sociológica das literaturas produzidas em língua portuguesa, com especial enfoque em África. Mostra o delineamento da noção de "póscolonial" não apenas em seu âmbito geral, mas aplicada principalmente ao campo da literatura, em especial da literatura produzida em língua portuguesa, apontando limites e possibilidades quanto ao uso da referida categoria para uma análise sociológica dos países africanos de língua oficial portuguesa. No campo das possibilidades se encontra uma nova forma de ver o mundo a partir de lugares ainda considerados periféricos pelo norte global, já com relação aos limites, através da trajetória de Inocência Mata, questiona-se se tal categoria não tenderia a reproduzir aspectos próprios da colonialidade, uma vez que a África continua a ser analisada a partir de seu processo colonizador.

PALAVRAS-CHAVE: Pós-colonial. Sociologia da literatura. Moçambique. Língua portuguesa.

RESUMEN: El objetivo de este artículo es cuestionar los límites y las posibilidades de las contribuciones teóricas "poscoloniales" al análisis sociológico de las literaturas producidas en portugués, con un enfoque especial en África. Muestra la delineación de la noción de "poscolonial" no solo en su alcance general, sino que se aplica principalmente al campo de la literatura, especialmente la literatura producida en portugués, señalando los límites y las posibilidades con respecto al uso de esta categoría para un análisis sociológico de Países africanos de habla portuguesa. En el campo de las posibilidades, hay una nueva forma de ver el mundo desde lugares aún considerados periféricos por el norte global. En relación con los límites, a través de la trayectoria de Innocence Mata, uno se pregunta si esa categoría no tenderá a reproducir aspectos proprios de la colonialidad mientras África continúa siendo analizada desde su proceso de colonización.

PALABRAS CLAVE: Postcolonial. Sociología de la literatura. Mozambique. Lengua portuguesa.

${ }^{1}$ Universidade Federal de Pernambuco (UFPE), Recife - PE - Brasil. Mestrando em Sociologia. ORCID: https://orcid.org/0000-0003-4108-6325. E-mail: marco.leal.cs@gmail.com 
ABSTRACT: The aim of this paper is to question the limits and possibilities of "postcolonial" theoretical contributions to the sociological analysis of literatures produced in Portuguese, with a special focus on Africa. It shows the delineation of the notion of "postcolonial" not only in its general scope, but applied mainly to the field of literature, especially literature produced in Portuguese language, pointing out limits and possibilities regarding the use of this category for a sociological analysis of the Portuguese-speaking African countries. In the field of possibilities, there is a new way of seeing the world from places still considered peripheral by the global north. In relation to the limits, through the trajectory of Inocência Mata, one wonders if such a category would not tend to reproduce its own aspects of coloniality as Africa continues to be analyzed from its colonization process.

KEYWORDS: Postcolonial. Sociology of literature. Mozambique. Portuguese language.

\section{Introdução}

No que concerne aos Estudos Culturais, destaca-se o surgimento de um campo teórico denominado Estudos/Teorias Pós-Coloniais. Delinear a noção de "pós-colonial" aplicada ao campo da literatura, em especial da literatura produzida em língua portuguesa. Busquei com isso compreender os diversos sentidos produzidos em relação ao termo pós-colonial quanto aplicado à análise da literatura, em particular nas literaturas africanas em língua portuguesa. Identificando as interpretações fundamentais no debate sobre a literatura produzida em língua portuguesa, com ênfase nas literaturas africanas. Apontando com isso, argumentos que dão destaque às possibilidades e aos limites das análises sociológicas das literaturas em língua portuguesa fundamentadas na categoria "pós-colonial".

A proposta que foi desenvolvida assenta-se justamente no questionamento dos limites e possibilidades de tais referências teóricas ao se colocar o foco da análise nas literaturas produzidas em língua portuguesa e nas literaturas africanas em sentido mais amplo, para além da delimitação linguística de caráter colonial, isto é, "literaturas africanas em língua portuguesa, espanhola, inglesa, francesa", etc. Os limites se ancoram no questionamento de, em que medida, os pressupostos das teorias pós-coloniais e seus aportes teóricos reproduziriam lógicas fundadas nas identidades nacionais, típicas da "era dos colonialismos"?

\section{Metodologia}

Para além das contribuições das diferentes vertentes pós-coloniais, e devido ao caráter bibliográfico da pesquisa, foi necessário um delineamento das principais possibilidades dadas 
à categoria pós-colonial nos seus diversos sentidos, principalmente em relação aos países africanos de colonização portuguesa, para compreensão das possibilidades teóricas que a categoria pós-colonial possui para a análise das referidas sociedades e como a literatura se configura num instrumento primordial de leitura dessas sociedades.

\section{Resultados e discussão}

Para Sérgio Costa (2013), a crítica pós-colonial teve início com intelectuais da diáspora negra ou migratória, vindos de países pobres da Europa ou da América do Norte. As teorias pós-coloniais encontraram espaço primeiramente nos estudos literários (Inglaterra e EUA) a partir dos anos de 1980. Após a sua contribuição nos estudos literários, essas perspectivas passaram a expandir-se para outras disciplinas, com contribuições de Homi Bhabha, Said, Spivak, entre outros e outras. A abordagem pós-colonial surge a partir dos debates entre os estruturalistas e pós-estruturalistas, criticando principalmente o processo de construção do conhecimento que, ao privilegiar os modelos de abordagens utilizados na Europa, reproduziria a relação colonial. Nesse sentindo, o estudo das "minorias sociais" e os processos de transformação nas sociedades não ocidentais continuariam a ser tratados em semelhança aos que se consideram centro (COSTA, 2013). O termo prefixo "pós" na expressão "pós-colonial" não indica simplesmente um "depois" cronologicamente falando, mas de uma reconfiguração no campo das discussões, no qual as relações de hierarquia acabam por ganhar significado. Já o "colonial" remete, para além do processo de colonização, as situações de opressão diversas podendo ser relacionadas ao gênero, etnia, raça, entre outras.

[...] as formas estabelecidas de produção do conhecimento contribuem para a reprodução da lógica interna do colonialismo na medida em que não apenas as experiências de minorias, mas também os processos de transformação social nas sociedades "não ocidentais" são analisados recorrentemente nos termos de suas relações funcionais ou de semelhança e diferença com aquilo que se definiu como centro da sociedade moderna (COSTA, 2013. p. 30).

A desconstrução da polaridade west/rest é um ponto nodal das discussões pós-coloniais. Segundo Costa, é a presença dessa perspectiva colonialista na produção do conhecimento que une as diversas abordagens no âmbito do debate pós-colonial. Do ponto de vista cronológico, o prefixo "pós" se refere as ex-colônias, que possuem condições pós-coloniais distintas. A desconstrução west/rest constitui um aspecto central no âmbito das relações coloniais. Tais relações tendem a se perpetuar mesmo após a extinção formal do estatuto colonial (COSTA, 
2013), mas se mantêm como modelo de produção do conhecimento e intervenção política. Existem diversas tarefas dos teóricos pós-coloniais e, segundo a análise de Sérgio Costa, citando a contribuição de Stuart Hall, podem ser destacadas duas:

1- Demonstrar a existência da polaridade west/rest, que se constrói no plano discursivo e se legitima na esfera política. Existe nesse sentido uma relação assimétrica e irreversível entre o oriente e o ocidente, em que o ocidente possui uma superioridade ontológica e imutável, que faz parte da própria construção lógica do mundo da vida.

2- Mostrar que a polaridade west/rest não oferece riscos do ponto de vista cognitivo, pois ofusca as relações de hierarquização existentes, ofuscando também o imaginário que se estabelece com relação ao resto do mundo.

\begin{abstract}
Essa polaridade tem papel determinante não apenas nos primeiros trabalhos modernos no campo das ciências humanas - de Kant a Weber, tomando-se, também, um dos fundamentos da própria ciência moderna, a qual toma as normas sociais, estruturas e valores encontrados nas sociedades qualificadas de ocidentais como parâmetro universal que define o que são sociedades modernas (COSTA, 2013 p. 31).
\end{abstract}

A desconstrução desse binarismo vem sendo seguida por vários pesquisadores e pesquisadoras. Desde o ensaio de Spivak Pode o Subalterno Falar? (1988), se desfez a expectativa de que surgiria uma nova perspectiva epistemológica dando voz ao indivíduo (póscolonizado). A autora se utiliza do exemplo da Índia, mostrando que não existe um indivíduo subalterno que busque a fala, na verdade existe uma heterogeneidade de indivíduos subalternizados que não possuem consciência plena de sua condição pré ou pós-colonial, uma vez que suas identidades foram construídas tendo como marco a violência colonial. O intelectual que se ancora nas teorias pós-coloniais busca compreender a dominação colonial como cerceamento da resistência, que torna a fala do indivíduo subalterno desqualificada. Cientes das impossibilidades anunciadas por Spivak, os teóricos do pós-colonial buscam alternativas para a desconstrução da perspectiva west/rest, que sejam distintas da mera inversão de posição desses sujeitos. Não se trataria de dar a voz ao oprimido, mas de uma descolonização da imaginação, que faz necessária numa crítica que não seja apenas anticolonialista. O póscolonial deve promover a desconstrução das fronteiras colonialistas e as criadas pela luta anticolonial, "ao mesmo tempo, todavia, procura-se superar essas instituições, disciplinas e categorias" (COSTA, 2013, p. 39).

Já Luciana Ballestrin tem como objetivo, em seu artigo América Latina e o giro decolonial (2013), apresentar em linhas gerais a genealogia das teorias pós-coloniais e a trajetória do Grupo Modernidade/Colonialidade, suas contribuições teórico/epistemológicas 
para as Ciências Sociais, propondo sempre uma renovação, principalmente na América Latina. A autora também mostra no seu trabalho a opção decolonial, bem como, suas contribuições no campo epistemológico, teórico e político. Um movimento importante foi o grupo sul-asiático que formava o Grupo de Estudos Subalternos e tinha como um dos principais objetivos, analisar criticamente a historiografia colonial da Índia feita pelos ocidentais europeus, criticando a perspectiva historiográfica do marxismo ortodoxo (BALLESTRIN, 2013). Nos anos de 1980, os estudos subalternos ${ }^{2}$ se tornaram conhecidos fora da Índia, através de trabalhos como o já citado ensaio de Spivak.

$\mathrm{Na}$ análise de Ballestrin, a origem do grupo Modernidade/Colonialidade se deu nos Estados Unidos entre 1990 e 1992, um grupo de intelectuais latino-americanos e americanistas fundaram o grupo Latino-Americano dos Estudos Subalternos, inspirados na vertente indiana. A América Latina foi assim inserida no debate pós-colonial, revisando as epistemologias previamente estabelecidas para as ciências sociais e humanidades. Incorporando temas abordados pelo grupo indiano, o grupo avançava para uma reconstrução da história latinoamericana. Essa reconstrução surgia como uma alternativa ao projeto teórico produzido pelos Estudos Culturais. O grupo colocou as lentes nas categorias de ordem política (classe, nação e gênero) que estavam invisibilizadas nos Estudos Culturais sob a categoria do "hibridismo".

Walter Mignolo já se mostrava como a voz mais radical do grupo (BALLESTRIN, 2013), demonstrando descontentamento com os estudos subalternos originais. Realizando sua crítica aos legados coloniais no continente americano, não acredita que os textos produzidos pelo grupo dos estudos subalternos deveriam ser apenas traduzidos e aplicados à realidade latino-americana. Para Mignolo é preciso buscar uma categorização crítica ao ocidentalismo que tenha seu lugar na análise da própria América Latina. Nesse momento, Walter Mignolo denuncia que o que os Estudos Culturais, Pós-coloniais e Subalternos não realizaram uma ruptura definitiva com relação aos valores eurocêntricos. Para o autor, o grupo latino-americano não deveria se espelhar na resposta indiana ao colonialismo, uma vez que a América Latina possuiu trajetórias de dominação e resistência distintas do que ocorreu na Índia.

Para ele, o grupo dos latinos subalternos não deveria se espelhar na resposta indiana ao colonialismo, já que a trajetória da América Latina de dominação e resistência estava ela própria oculta no debate. A história do continente para o desenvolvimento do capitalismo mundial fora diferenciada, sendo a primeira a sofrer a violência do esquema colonial/imperial moderno (BALLESTRIN, 2013, p. 95-96).

${ }^{2} \mathrm{O}$ termo subalterno foi tomado emprestado de Gramsci, aqui o termo é compreendido como classe ou grupo desagregado e episódico que tem uma tendência histórica a unificação sempre provisória, que tem como objetivo o fim da hegemonia da classe dominante. 
A autora também destaca que a América Latina possui outras relações de colonialidade por parte do novo império estadunidense, apesar deste ter sido também uma colônia americana. Devido a diversas divergências, o grupo latino-americano se dissolveu, alguns de seus antigos membros e outros teóricos latino americanos acabaram por fundar o grupo Modernidade/ colonialidade (BALLESTRIN, 2013). "Com pouco mais de dez anos de existência, o grupo compartilha noções, raciocínios e conceitos que lhe conferem uma identidade e um vocabulário próprio, contribuindo para a renovação analítica e utópica das ciências sociais latinoamericanas do século XXI" (BALLESTRIN, 2013, p. 99). Tornava-se evidente a necessidade de transcender, em outras palavras, se descolonizar da epistemologia e do cânone ocidental e pensar as questões do sul a partir do próprio sul. Entretanto, Foucault e Gramsci permaneceram como referências do grupo sul-asiático o que impedia a radicalização teórica de ambos os grupos, o indiano e o latino-americano, antes de suas rupturas que culminaram no grupo Colonialidade/Modernidade.

A proposta decolonial para Ballestrin significa um movimento de resistência teórico, prático, político e epistemológico. A lógica da modernidade/colonialidade não deve ser confundida com a rejeição à criação humana realizada no Norte global e associada com o Sul. Ela deve ser lida como um contraponto à tendência histórica da divisão do trabalho científico no âmbito das ciências sociais, onde o Sul se mostra como fornecedor de experiências e o Norte se configura como elemento teorizador: a "perspectiva decolonial, que fornece novos horizontes utópicos e radicais para o pensamento da libertação humana, em diálogo com a produção de conhecimento" (BALLESTRIN, 2013, p. 110). Diversos autores e autoras tem produzido atualmente teorias que questionam o universalismo etnocêntrico e eurocêntrico. Esses tem construído um conjunto de elaborações denominadas Epistemologias do Sul, valorizando perspectivas "trans-modernas" (MIGNOLO, 2010) que propõem uma descolonização das ciências sociais.

Entrando no campo da literatura atrelada à categoria pós-colonial, a análise de Hamilton (1999) diz que, embora os PALOP ${ }^{3}$ possuam similitudes com outras ex-colônias, Cabo Verde, Guiné Bissau, Moçambique, Angola e São Tomé e Príncipe, possuem em conjunto, e individualmente, singularidades marcantes no contexto africano. Uma diferença importante, localizada nas áreas da expressão cultural e em particular na expressão literária, é a presença de intelectuais mestiços e brancos nas ex-colônias portuguesas, algo que o autor vai chamar de "intelligentsia" multirracial, em que se destacam Angola e Moçambique. Em meados dos anos

${ }^{3}$ Países Africanos de Língua Oficial Portuguesa. 
de 1940, intelectuais negros, mestiços e brancos se uniram sob a bandeira da luta anticolonial.

Quanto às semelhanças com as colônias de França, estava a política de assimilação estabelecida tanto por Portugal quanto pela França. Entretanto, ao contrário do que aconteceu em Angola e Moçambique, poucos colonos e filhos de colonos francófonos se tornaram escritores pós-coloniais. As peculiaridades históricas das cinco ex-colônias portuguesas contribuíram para a singularidade da sua expressão literária, “era a expressão literária de reivindicação cultural, protesto social e combatividade que vinha preparando a cena nos cinco PALOP para a atual escrita pós-colonial" (HAMILTON, 1999, p. 16).

Naturalmente, a produção literária da época se opunha ao regime colonial. Nos PALOP, devido à vitória dos movimentos de libertação, surgiu uma literatura que celebrava a derrota do regime colonial, enaltecia a revolução social e a reconstrução nacional nesses países. Junto com obras de caráter nacionalista e nativista, surgiram obras de caráter mais intimista que, de caráter experimental e reformista, levaram alguns autores nacionais a reescreverem e reinventarem a África e seus respectivos países. Os cidadãos e cidadãs desses países precisam conviver com instituições sociais e culturais que são marca indelével do colonialismo, uma vez que as próprias fronteiras geográficas desses países foram estabelecidas pelos seus colonizadores. Dentre essas marcas está o uso da língua do colonizador, questão que perturbou intelectuais africanos e africanistas, uma vez que o português foi defendido como língua oficial dos países pertencentes ao PALOP, que consideram a língua portuguesa como também sua. Nesse sentido, o autor expõe o questionamento existente na época de publicação do seu dossiê: pode existir uma literatura autenticamente africana escrita numa língua não africana?

A resposta obviamente é sim, "pois tal literatura já existe” (HAMILTON, 1999, p. 17). Os fatores políticos, sociais, econômicos e culturais são pontos essenciais que dão relevo à problemática em torno das teorias pós-coloniais, dada a importância da literatura anos após a independência dos países do PALOP, a crescente tendência dos escritores do momento das independências em reescrever o passado pré-colonial e colonial nas sociedades em construção nesses cinco países. Nesse sentido, o autor destaca a contribuição de Pepetela, autor angolano, e sua perspectiva nacionalista ainda embrionária na sociedade angolana. Assim narrar o passado acabou se tornando válido dentro das perspectivas pós-coloniais. Destaca-se, nesse sentido, o esforço de autores e autoras na tentativa "re-mitificar" a história dos cinco países do PALOP, destaca ainda a contribuição de Mia Couto e Ungulani Ba Ka Khosa, ambos moçambicanos. Essa tentativa de "re-mitificar" ou reescrever o passado pode ser considerada uma estratégia frente às distorções estereotipadas desenvolvidas pelo colonizador europeu, veja como exemplo a obra No Coração das Trevas (1902) de Joseph Conrad. 
Alguns dos melhores exemplos desta re-mitificação verificam-se nos romances dos moçambicanos Mia Couto e Ungulani Ba Ka Khosa. Ualalapi, o termo tsonga para "aquele que dorme", o primeiro romance de Ba Ka Khosa, ostenta, no âmbito das re-mitificações pós-coloniais, elementos estilísticos e temáticos do realismo mágico latino-americano. E Mia Couto, no seu Terra Sonâmbula, re-mitifica, por meio de cenas surrealistas e situações fantasiosas, um episódio da recente história pós-colonial de Moçambique (HAMILTON, 1999, p. 18).

Essa re-mitificação é um componente norteador do neotradicionalismo (HAMILTON, 1999) que caracteriza importantes elementos da condição pós-colonial. De modo paradoxal, nesses novos discursos literários, surge o questionamento acerca das estruturas herdadas do colonialismo e, por trás deste, o questionamento dos regimes de administração que se instalaram nos países do PALOP, após suas respectivas independências.

Recortando a análise para as literaturas moçambicanas, para Fátima Mendonça (2008), o surgimento da literatura em Moçambique se dá de fato no fim dos anos de 1940. Após as primeiras manifestações, já é notável a literatura como um sistema (um corpo de autores, leitores, obras que circulam e uma crítica). É importante destacar que a literatura que estava se desenvolvendo em Moçambique não rompe com a literatura portuguesa, mas sim, com a literatura colonial, aquela produzida pelos portugueses em solo africano. Essa literatura colonial supervalorizava o homem branco, sua presença e suas ações em África. Na década de 1940, começa a circular o gentílico "moçambicano" e a pretensão de uma ideia de nação, notadamente na poesia de José Craveirinha e Noémia de Souza. A literatura produzida nesse momento era principalmente uma literatura engajada, não apenas culturalmente, mas politicamente: "a reivindicação que era feita era a reivindicação de um território cultural, que obviamente implicava um território político, claramente tendo em conta que se tratava de um espaço subjugado, de um espaço dominado" (NOA, 2014, p. 348).

$\mathrm{Na}$ análise de Inocência Mata (2010), “[...] a literatura é um produto da vida social, estando, portanto, ligada a contextos específicos e em diálogo com outras séries sociais" (MATA, 2010, p. 299). Entretanto, Inocência Mata elenca a falácia relacionada ao método histórico, colocado bastante em prática nos Estados Unidos. Esse método poderia resumir a literatura à forma de "objeto cultural” (MATA, 2010), reduzindo a literatura a uma expressão da cultura, entretanto, é necessário pensar no que está fora do texto. Nesse sentido, Inocência Mata analisa o conceito de literatura sob duas questões, ou um duplo ponto de vista:" 1) a partir do contexto da sua produção; 2) de que decorre a sua relação com o conhecimento" (MATA, 2010, p. 300).

A complementaridade dos estudos literários, culturais e sociais se dá por três 
perspectivas, segundo Inocência Mata, respondendo aos estudos da literatura em âmbito geral e das literaturas periféricas de modo mais específico. A primeira seria relacionada aos aspectos extratextuais que expressam uma realidade vivida por quem escreve. Mesmo escrevendo uma ficção há realidade histórica naquele texto que de alguma forma vai ser apreendida pelo leitor. A segunda perspectiva refere-se a atender à uma necessidade do leitor comum, formado dentro da literatura canônica ocidental, que não possui o conhecimento básico sobre os países onde se desenvolvem essas literaturas, o que acaba transformando o estudo dessas literaturas numa fonte de conhecimento sobre os seus locais de produção. Por fim, a partir disto, se salda uma dívida que a consciência histórica ilumina a problemática do conhecimento da sociedade no que diz respeito à alteridade com as margens periféricas (MATA, 2010).

Sobre o uso da categoria para pós-colonial para a análise das literaturas produzidas nos países de colonização portuguesa, a autora vai elencar em seu texto Estudos pós-coloniais desconstruindo genealogias eurocêntricas (2014) uma desestabilização das perspectivas colonizadoras chamando a atenção para o caráter perverso de certas perspectivas das ciências como "Cânone e Universal", "Cosmopolitismo ou Globalização":

Eis porque se torna fundamental discutir algumas ideias tidas como adquiridas entre os estudiosos das literaturas periferizadas, como as africanas em português, ou menorizadas, como a de brasileira afro descendente, e seus agentes e atores (...) tendo em conta a tendência para a classificação judicativa que decorre do processo de hierarquização com base em critérios tidos como "universalistas" que propõem a rarefação identitária decorrente, segundo os seus arautos, da dinâmica da globalização (MATA, 2014, p. 38).

Essas categorias, dentro de uma perspectiva eurocêntrica, podem ser entendidas como um universalismo no qual "os espaços ex-colonizados continuam a ser nomeados segundo signos e sinais do ex-colonizador" (MATA, 2014, p. 38), o que propõe a todos uma imitação ao modelo ocidental, como única possibilidade de saída para explicação para as questões do nosso tempo. As discussões acerca das perspectivas pós-coloniais, principalmente as que advêm dos ex-impérios, convergem em dois aspectos, o primeiro na necessidade de diálogo com as epistemologias do sul para a construção do saber. Os estudos culturais estão se reorganizando em outros alicerces, que não as linearidades e dualismos dos clássicos, que funcionariam como elemento de perpetuação e supremacia de uma estrutura ideológica e histórica das sociedades. Essa antes citada estrutura que é afirmada nas relações de poder atuais, chamadas de relações pós-coloniais, possuem relação com as ciências sociais, humanas e com os estudos literários, não obstante dos seus destinadores (ocidente) serem entidades imaginárias, construções discursivas enquanto objeto e sujeito do discurso. 
O ocidente na visão da autora é, assim como o oriente, uma construção imaginária, entretanto, devido aos aspectos ideológicos já elencados, o ocidente se torna um "fato histórico" (MATA, 2014), uma evidência, em detrimento dos elementos não ocidentais, considerados míticos, desmerecidos pelo cânone. Nesse sentido, colocar o pós-colonial como ideologia foi uma tentativa de trazer a luz elementos do discurso epistemológico que são eminentemente eurocêntricos, formulando explicações que ajudem a esclarecer as formas como se dão as relações hierárquicas de poder e dominação (MATA, 2014). Isso se configura para Inocência Mata como um modo de "percorrer os trilhos que levam a uma geocrítica do eurocentrismo" (MATA, 2014, p. 32).

Quando analisadas nas entrelinhas, essas geografias culturais permitem ainda uma reflexão sobre o processo de formação da nação, num percurso cultural. No caso dos estudos literários é importante destacar, antes de qualquer rótulo local e regional, que o escritor é um sujeito de seu tempo e que "a literatura é uma produção social, parte integrante de uma realidade e de uma história nunca neutras" (POLAR, 2000, p. 20). Existe aqui, na análise das literaturas através de uma perspectiva pós-colonial, uma reivindicação da dimensão social e histórica da obra literária, surge também com isso uma reivindicação de autonomia teórica atrelada à ideia de dependência cultural, sobretudo no campo das ciências principalmente no que se relaciona com as identidades. A história da literatura e a crítica literária devem se preocupar, segundo a autora, com as relações já passadas e com as relações presentes, pensando no que pode vir depois.

É esse desvio em direção a um outro sentido, que propõe a inclusão de outras racionalidades, que têm percorrido muitos estudiosos desses espaços, com especial ênfase para os das literaturas e culturas latino-americanas, quando consideram, nas entrelinhas do seu diverso e variado corpo de reflexões sobre produções dessas geografias culturais, que o estudo do lugar de cada produção estética passa, também, por uma reflexão sobre o percurso cultural de uma geração ou uma nação (MATA, 2014, p. 32).

Sobre as possibilidades epistemológicas do pós-colonial, Inocência, em seu texto Localizar o "pós-colonial" (2016), elenca a possibilidade de tais teorias investirem no questionamento do cânone, para desconstruir as análises hierarquizantes e desigualmente globalizantes que não considera relevantes os escritores africanos que não são publicados em Portugal. Vários críticos e jornalistas se baseiam apenas no que é publicado em Portugal. Isso também faz parte de uma estrutura muito maior ligada à academia, quando estudos sobre uma determinada autora ou autor, acabam dando a esta legitimidade acadêmica. Os estudos sobre alguma escritora ou escritor acabam dando a este passaporte para o sistema canônico. É também 
a academia que fornece a hierarquização do lugar de determinado autor no sistema da literatura, quando afirma que foi influenciado por outros autores. Não que com isso se desconsidere que as influências literárias existam, uma vez que as próprias perspectivas pós-coloniais advogam que tudo parte de um lugar de enunciação, mas a ideia de influência de um escritor da alta literatura na obra de um novo escritor garante esta validade, como um passaporte de qualidade literária. Esse tipo de abordagem acaba reificando o lugar subalterno das literaturas produzidas nos países africanos e a crítica possui um papel fundamental nesse processo. Segundo Inocência, a crítica jornalística

[ela é caracterizada por uma] base ostensivamente eurocêntrica e intenção hierarquizante, que parece obedecer a uma lógica globalizante, mas também cumprindo interesses de grupo, decorre do facto de muita crítica da literatura africana se fazer, ainda, por via de mediações do "centro". Em rigor, este continua a funcionar como "centro metropolitano", ao qual convém a rarefacção (ou desvanecimento) do real histórico e a desconsideração do fator identitário, divisa da literatura "sem fronteiras", que propõe a dissolução da diversidade cultural - que é, diz-se, realidade pós-moderna e pós-colonial (MATA, 2005, p. 13).

Ainda sobre a legitimidade dos autores que estão produzindo essas literaturas, Inocência afirma que caímos sempre na mesma relação colonial de dominação: “o estudo de determinado autor na academia confere-lhe o passaporte para o sistema canônico" (MATA, 2016. p. 38). Hoje já é de conhecimento geral que a Colonialidade do Poder não é apenas política e econômica, mas uma Colonialidade Global, antes de tudo epistemológica. E na intenção de contrariar essa hegemonia que surge a necessidade de contextualização da produção do conhecimento, para que se busque traduzir novas formas de conhecimento e racionalidade, para a compreensão de fenômenos socioculturais contemporâneos: observáveis através das relações de poder entre realidades e objetos culturais, vistos como socialmente construídos e historicamente localizados, segundo os pressupostos dos estudos culturais. A partir da negação hegemônica surge o conceito de "história universal" que existe na intenção de ignorar as "histórias locais", uma das premissas da colonialidade do saber (MATA, 2016).

A perspectiva universalizante das teorias e elaborações conceituais dos Estudos Subalternos, aplicadas no estudo dos objetos culturais de sociedades que emergiram da situação colonial. Parece para a autora, e com razão, que a história universal ainda se resume como a história europeia. Foi essa insatisfação que levou a autora a trabalhar com a investigação dos saberes a partir de práticas e registros etnográficos. Partindo da observação do contexto da situação, e não de teorias preestabelecidas.

Com essa perspectiva foi possível analisar os significados das interações dos sujeitos e 
a sua produção em contexto, e trabalhar na formulação de outros conceitos críticos que permitissem traduzir esses contextos. Para Inocência Mata é necessário provincializar paradigmas epistemológicos, alargando o campo das representações marcadas pelas ideias das epistemologias do Sul, em contraposição à "compulsão europeia" de encaixar por colonial o resto do mundo que não é a Europa. Mata propõe, em contraponto, uma leitura alternativa de diferentes experiências históricas, nas quais podemos localizar alguns dos limites, (desconsiderando o historicismo como categoria universal). É nesse sentido, que do ponto de vista africano, os estudos pós-coloniais devem ser contestados a partir da sua própria matriz o "colonialismo", definido aqui como a prática do imperialismo.

Mas um ponto a ser destacado sobre os limites é um dos questionamentos da própria autora: “continuará a África a ser pensada a partir das suas relações coloniais?” (MATA, 2016, p. 44). Alguns teóricos recusam a expressão pós-colonial para se referir à África, afirmando que esta continua a ser pensada a partir do colonial, existindo a necessidade de restituir a História das sociedades africanas, para contrariar a ideologia (neo)colonial (MATA, 2016). Mantendo-se crítica à perspectiva historicista, a autora se detém nas ideias de transformação e rastreio de continuidades que fundamentam as mudanças. São justamente essas ideias que parecem não acontecer nos estudos relacionados à África que se preocupam apenas com as possíveis "faltas", temática obsessiva relacionada ao desenvolvimento quando se fala das realidades africanas. O "historicismo é, na verdade, uma armadilha nos estudos sobre o Sul" (MATA, 2016, p. 45)

A questão que decorre dessa relação de desigualdade é: "até que ponto funcionarão, neste contexto, os estudos pós-coloniais como legitimação da hegemonia epistemológica do Ocidente?" (MATA, 2016, p. 46). Desde a construção do termo "pós-colonial”, que é mais "pacificador" do que expressões como imperialismo ou neocolonialismo, essa questão está ligada necessariamente a outros campos relacionados à África, como suas opções de desenvolvimento impostas pelos "doadores" internacionais, por meio de uma imposição simbólica de valores hegemônicos que acabam por se reproduzir na perspectiva hierarquizante Norte-sul, que, de certa forma, estariam sendo legitimadas pelas próprias categorias póscoloniais que tentariam findá-las. Outras possibilidades metodológicas estão sendo desenvolvidas até o momento como alternativas aos estudos relacionados à literatura africana, principalmente ao que diz respeito à utilização de narratividades locais e trabalhos etnográficos que permitam compreender a realidade específica que ali se revela, repensando se as teorias pós-coloniais teriam, portanto, um papel tão fundamental na análise das literaturas produzidas nos países africanos: "esta situação, tão diferente, tem me permitido proceder muitas 
relativizações, operando um desvio em direção a formas alternativas de racionalidade e pensar a partir de lugares até então desconhecidos para mim” (MATA, 2016, p. 48).

\section{Considerações finais}

Ficou evidente desde o início, a dificuldade encontrada em trabalhar com essa categoria, uma vez que se localiza em um campo ainda em construção e dentro de debates em que dificilmente existem consensos. O que torna ainda mais difícil destacar as possibilidades e limites que o presente projeto tinha como proposta norteadora. Diversos pensadores e pensadoras que trabalham o pós-colonial possuem ideias divergentes quanto aos seus usos, principalmente no que tange às literaturas produzidas em língua portuguesa e, de modo ainda mais pungente, as literaturas produzidas em língua portuguesa nos países africanos que passaram por um processo colonizador português. Na tentativa de tecer algumas generalizações, destacaremos aqui alguns elementos que de forma ainda panorâmica nos fornecem um quadro de possibilidades e limites quanto ao uso dessa categoria.

As possibilidades já se mostram antes mesmo de entrarmos nos estudos sobre a literatura, uma vez que as teorias pós-coloniais têm em comum a luta pelo processo de descolonização da mente. Uma nova forma de ver o mundo a partir de lugares ainda considerados periféricos pelo norte global. O questionamento canônico europeu nos estudos literários e nas ciências sociais é ainda um tabu enfrentado pelas teorias pós-coloniais que se fundamentam na derrubada das perspectivas canônicas e homogeneizantes.

Os limites foram apontados principalmente por uma análise da trajetória de Inocência Mata nos estudos pós-coloniais para a análise das literaturas em língua portuguesa produzidas no continente africano. Nos trabalhos de análise mais recentes realizados por Inocência há um evidente questionamento sobre o limite da categoria pós-colonial que ela mesma utilizou durante anos para a análise das literaturas africanas produzidas em língua portuguesa. Para essa autora, existe um questionamento que dever ser feito: tal categoria não tenderia a reproduzir aspectos próprios da colonialidade, uma vez que a África continua a ser analisada a partir de seu processo colonizador? Um outro limite que também se relaciona com o anterior é a construção de uma visão sobre os países africanos sempre na perspectiva da falta, como se o continente africano não possuísse a capacidade de explorar e superar suas próprias problemáticas. Nesse sentido é necessária uma teoria pós-colonial ou um olhar para a África dentro da própria África? 
Pensar nos limites requer mais debate, uma vez que estão sendo colocadas em xeque várias contribuições já "canônicas" dentro das teorias pós-coloniais, como os próprios trabalhos de Inocência Mata. Considero que as críticas realizadas pelo grupo Modernidade/Colonialidade servem para aprofundar as reflexões nas possíveis contradições existentes nas teorias póscoloniais

\section{REFERÊNCIAS}

APPIAH, Kwami Anthony. Na casa de meu pai: a África na filosofia da cultura. Rio de Janeiro: Contraponto. 1997.

BALESTRIN, Luciana. América Latina e o giro decolonial. Revista Brasileira de Ciência Política, n. 11, mai./ago. 2013.

BOKOLO, Elikia. História e historiografia africana. Revista de Teoria da História, v. 18, n. 2, p. 267-288, 2017. Entrevista concedida a Marcello Felisberto Morais de Assunção.

BORGES, Antonádia et al. Pós-Antropologia: as críticas de Archie Mafeje ao conceito de alteridade e sua proposta de uma ontologia combativa. Revista Sociedade e Estado, Brasília, v. 30, n. 2, 2015.

CASIMIRO, Isabel; CRUZ E SILVA, Teresa. Uma escola de conhecimento social: o CEA e as ciências sociais em Moçambique. Entrevista concedida à Eliane Veras e Remo Mutzenberg, Maputo, 2011. (Transcrição).

COSTA, Sérgio. "(Re)Encontrando-se nas redes? As ciências humanas e a nova geopolítica do conhecimento." In: ALMEIDA, Júlia; MIGLIEVICH-RIBEIRO, Adelia; GOMES, Heloisa Toller (Orgs). Crítica pós-colonial: panorama de leituras contemporâneas. Rio de Janeiro: 7Letras, 2013.

HAMILTON, R. P. A literatura dos PALOP e a teoria pós-colonial. Via Atlântica, n. 3, p. 12-22, 1999.

LUGARINHO, Mário César. Entrevista com Inocência Mata. ContraCorrente: Revista de Estudos Literários e da Cultura, n. 7, p. 228-235, 2015.

KANDJIMBO, Luís. O Endógeno e o Universal na Literatura Angolana. 2001. Disponível em: http://www.nexus.ao/kandjimbo/SEMINARPAR.pdf. Acesso em: 13 abr. 2019.

KANDJIMBO, Luís. Para uma crítica dos estudos pós-coloniais (Contra os Cânone ocidental, outros cânones e globalética). In: GARCÍA, F.; MATA, I. (Orgs.). Pós-colonial e pós- 
colonialismos: propriedades e apropriações de sentido. Rio de Janeiro: Dialogarts publicações 2016.

MATA, Inocência. A crítica literária africana e a teoria pós-colonial: um modismo ou uma exigência? In: A literatura africana e a crítica pós-colonial: reconversões. Luanda, Editoria Nzila, 2007.

MATA, Inocência. "Literatura" In: SANSONE, L; FURTADO, C. A. Dicionário crítico das ciências sociais dos países de fala oficial portuguesa. Salvador Edufba / Publicações ABA, 2014.

MATA, Inocência. Estudos pós-coloniais: Desconstruindo genealogias eurocêntricas. Civitas, Porto Alegre v. 14, n. 1, p. 27-42, 2014.

MATA, Inocência. Localizar o "Pós-Colonial". In: GARCÍA, F.; MATA, I. (Orgs.). Póscolonial e pós-colonialismos: propriedades e apropriações de sentido. Rio de Janeiro: Dialogarts publicações, p. 32-50, 2016.

MENDONÇA, Fátima. Em busca de uma identidade: literatura, nação e mestiçagem em Moçambique. Entrevista concedida à Eliane Veras, Lisboa, 2012. (Transcrição).

MENESES, Maria Paula. A configuração da colonialidade do saber: questionando o sentido da descolonização a partir de Moçambique. In: GARCÍA, F.; MATA, I. (Orgs.). Pós-colonial e pós-colonialismos: propriedades e apropriações de sentido. Rio de Janeiro: Dialogarts publicações, 2016.

MIGNOLO, Walter. Desobediencia epistémica: retórica de la modernidad, lógica de la colonialidad y gramática de la descolonialidad. Buenos Aires: Edicionesdel Signo, 2010.

NEWITT, Malyn. História de Moçambique. Lisboa, Mem Martins, 2012.

NOA, Francisco. Surget et Ambula: literatura e (des)construção da nação. (Entrevista concedida a Eliane Veras e Remo Mutzenberg). Estudos de Sociologia, (Recife), número 20, v. 2, p. 341-369, jan./dez., 2014.

POLAR, Antônio Cornejo. O Condor Coa: literatura e Cultura na América Latina. Organização de Mario Valdés. Belo horizonte. Editora da UFMG, 2000.

SAMO, Graça. Desafios para o movimento de mulheres em Moçambique. Entrevista concedida a Remo Mutzenberg, Maputo, 2011. (Transcrição).

SOARES, E.V. Embora lidando com literatura, você está fazendo sociologia. Civitas, v. 14, n. 1, p. 81-92, 2104. 


\section{Como referenciar este artigo}

LEAL, Marco Aurelio de Oliveira. O "pós-colonial" como categoria de análise sociológica das literaturas palopianas: possibilidades e limites. Rev. Sem Aspas, Araraquara, v. 8, n. 1, p. 115130, jan./jun. 2019. e-ISSN: 2358-4238. DOI: 10.29373/sas.v8i1.12694

Submetido em: 24/03/2019

Aprovado em: 29/05/2019 